\title{
LA REGIÓN DE PURUÁNDIRO EN EL SIGLO XIX. ECONOMÍA Y SOCIEDAD RURAL (UN ACERCAMIENTO A TRAVÉS DE LA VISIÓN DE HERIBERTO MORENO GARCÍA)
}

HERIBERTO MORENO GARCIA

"Patrones del arrendamiento rural en Michoacán. Puruándiro y su región, 1821-1910". En Relaciones, Zamora, El Colegio de Michoacán, № 43, verano, 1990. pp. 39-73.

"Negocios en participación en el campo michoacano". En Ricardo Avila Palafox, et. al. comps. Las formas y las políticas del dominio agrario. Homenaje a Francois Chevalier. Guadalajara, CEMCAUNAM-U de G, 1992a. pp. 51-68.

"Los préstamos particulares en el campo y la formación de la región de Puruándiro". En Sergio Zendejas (Coordinador), Estudios Michoacanos IV, Zamora, El Colegio de Michoacán, 1992b. pp. $19-44$.

"Compradores y vendedores de tierras, ranchos y haciendas en el Bajio michoacano guanajuatense, 1830-1910". En Beatriz Rojas (Coordinadora). El poder y el dinero. Grupos y regiones en el siglo XIX. México, Instituło Mora, 1994a. pp. 256-287. "Implementos y herramientas agrícolas en el norte de Michoacán, 1826-1910". En Relaciones, Zamora, El Colegio de Michoacán, № 59, verano, 1994b. pp. 83-111.

\section{II} In algún momento del segundo lustro de la década de los ochenta, Heriberto Moreno García, profesor-investigador de El Colegio de Michoacán, dió inicio a un proyecto de investigación sobre la Economía y Sociedad Campesina en el Centronorte de Michoacán durante el siglo XIX. Los resultados provisionales de esta empresa fueron apareciendo en una serie de ensayos entre 1990 y 1994. Aunque el producto entero nunca germinó en una obra de conjunto, puede considerarse una fortuna disponer de avances significativos de lo que posiblemente hubiera llegado a ser uno de sus mejores estudios. En noviembre de 1996, después de un padecimiento que afectó seriamente su salud, la muerte cegó su vida.

Acreditado por la labor desarrollada en las áreas de historia regional y agraria, Heriberto Moreno García era originario del extremo occidental de Michoacán, lu- 
gar al que regreso desde finales de los años setenta para establecer residencia permanente. Maestro en historia por la UNAM, fue miembro fundador al lado de Luis González y González, en 1979, de El Colegio de Michoacán en la ciudad de Zamora. Uno de los proyectos más ambiciosos y notables en el campo de las humanidades en México, institución de la cual no se separaría desempeñando tareas administrativas, de investigación y docentes. Su amplia producción historiográfica se localiza en varios libros y en numerosos artículos dispersos en revistas, memorias de congresos y compilaciones, destacando los de tema michoacano y del agro. Entre estos figuran de manera relevante: Guaracha. Tiempos viejos, tiempos nuevos (1980; $2^{\text {a }}$ edición, 1994); Cotija (1980); Haciendas de tierra y agua (1989); la introducción, selección y notas de los libros Los agustinos, aquellos misioneros hacendados (1985) y En favor del campo (1986), y en colaboración con otros fue el coordinador y autor del tomo IV de la Historia General de Michoacán (1989).

La presente reseña tiene como objetivo realizar un recuento y análisis de conjunto de estos ensayos, en el entendido de evaluar sus propuestas y limitaciones, destacando los aportes y las vetas que abrieron, además de pretender establecer las rutas por las que se conducía el esquema general del proyecto.

Los cinco artículos que nos ocupan fueron publicándose, sin ningún orden aparente, obedeciendo a requerimientos de participación en congresos y al proceso inherente a toda investigación histórica. Los asuntos expuestos en los títulos de los artículos presentan un amplio abanico de tema agrario y agrícola de Michoacán en el siglo XIX, que comprenden asuntos de rentas de tierra, creación y desmembración de compañías, crédito rural, compraventas de bienes fundiarios y de tecnología en la agricultura.

La composición de los ensayos responde a una estructura idéntica y que el autor hace explícita, procedimiento que el lector agradece al facilitarle la comprensión unitaria del texto. En todos ellos, en términos generales, se desprenden la integración de los siguientes elementos: una introducción, los alcances del trabajo, la precisión del ámbito regional y el espacio cronológico, los propósitos del estudio, la información del corpus documental manejado, el método y la técnica aplicada, la definición de conceptos, los contenidos de análisis y las conclusiones o reflexiones finales. Los ensayos, sin excepción, contienen gráficas, tablas, mapas y referencias documentales, lo que enriquece y sustenta los trabajos. 
La condición de ser resultados previos prefiguró una confección con base en criterios de una selección bibliográfica. Los libros consultados definen la preocupación de Moreno por establecer los fundamentos teóricos de su argumentación y de intentar hacer una revisión comparativa con otros estudios desarrollados en otras regiones de México. Entre los primeros están autores como Kostas Vergopoulos, Samir Amin, Witold Kula y Vladimir Ilich Lenin. En los segundos, sirven de apoyo la historiografía relacionada con el tema, de autores como David A. Brading, Gisela von Wobeser, Jorge Basave y Jan Bazant. Sin contar con material de apoyo regional y de sustento.

En contraste con el empleo limitado de bibliografía, la masa documental utilizada es importante. El armazón de los trabajos se teje con materiales provenientes básicamente del Archivo de Notarias de la ciudad de Morelia y del Archivo Histórico del Poder Judicial de Michoacán. Las partidas y procesos legales recopilados en ambos acervos arroja un conteo total de 645 documentos. Clasificados por tipo de contrato y expediente se desprenden 110 partidas de arrendamiento, 36 de conformación de compañías, 134 de préstamos, 319 de compraventas de bienes fundiarios y 46 inventarios judiciales.
En cada artículo de Moreno se contempla un asunto bien definido pero en común se comparte tópicos que los unifica, cualidad que permite distribuir los temas expuestos de manera adecuada. Intentemos inspeccionar bajo esta premisa la obra de conjunto e individual.

\section{LA CONSTRUCCIÓN DE LA}

REGIÓN DE PURUÁNDIRO

La región de Puruándiro se ubica en la parte norte del estado de Michoacán. Fisiográficamente corresponde a la cuenca del río Lerma en el vértice meridional. La prolongación septentrional de la cadena montañosa del Sistema Volcánico Transversal definió que este planalto, situado hacia los 1700 metros sobre el nivel del mar, se conformara en una serie de valles, lomas y altozanos. Un sistema hidrológico integrado por ríos de cauce mediano y de arroyos de corriente temporal, enfilan hacia el Lerma los remanentes líquidos que el hombre no utiliza.

Una disposición espacial también contemplada por Moreno es la jurisdiccional administrativa, de acuerdo a la división política del Estado de Michoacán en el transcurso del siglo XIX. La historia territorial demuestra que a pesar de las innumerables modificaciones el Partido o Distrito de Puruándiro, según la adecua- 
ción imperante, casi siempre conservó un área nuclear constituida por los municipios de Puruándiro, Angamacutiro, Panindícuaro, (Huango) Villa Morelos, Huaniqueo y Coeneo. El indiscutible centro político, administrativo y comercial del espacio rural circundante, es siempre la ciudad de Puruándiro. Fuera de este núcleo la extensión cubre, debido a las articulaciones del mercado, a las localidades de Moroleón, Uriangato y Yuriria, espacios externos a la frontera estatal ubicados en el vecino estado de Guanajuato.

En el caso de la región de Puruándiro los criterios jurisdiccionales y fisiográficos en cierta medida presentaban desde sus inicios elementales coincidencias de unidad y se ajustaban bien y sin dificultades a la elección y demarcación del área de estudio. Esta ventaja no dejó satisfecho a Moreno aunque dispone de ella. Para él la zona es un producto histórico cuajado en el siglo XIX por un proceso de estructuración de factores y patrones de producción, distribución, intercambio y consumo que le darían sentido de área geoeconómica. ${ }^{1}$

\section{COMPONENTES REGIONALES}

La región geoeconómica de Puruándiro inició su integración durante el período colonial. Desde el siglo XvII la propiedad rural se caracteriza por el fraccionamiento y la vocación ganadera. El siglo XVIII observará pocas modificaciones de las estructuras agrarias. Debido a su estratégica posición entre Michoacán y Guanajuato la zona se convirtió en corredor natural de la intensa relación comercial entre ambas entidades. Esta condición mereció la atención de los bandos beligerantes de la guerra de independencia que pretendieron asegurar su control. La contienda ocasionó allí innumerables desastres. No obstante, la recuperación subsecuente después de las hostilidades fue acelerada obedeciendo a la misma ventajosa situación geográfica. ${ }^{2}$

El siglo XIX inaugura entre las transformaciones más notables de la región de Puruándiro la modificación del anterior modelo ganadero por la vigorización del sector agrícola. ${ }^{3}$ La gran propiedad privada, en comparación con otras regiones de Michoacán, convive con un considerable conjunto de ranchos y propiedades de dimensión variable, importante característica regional, estableciendo un vínculo contradictorio de admisión y rechazo según las condiciones prevalecientes. ${ }^{4} \mathrm{El}$

1. Moreno García, op. cit., 1992b. p. 26.

2. Idem, pp. 27-28.

3. Idem, p. 28.

4. Moreno García, op. cit., 1990. p. 48. 
ciclo laboral agrícola atendía la secuencia estacional anual. La siembra del maíz iniciaba a la llegada de las lluvias y su recolección en diciembre y enero; mientras el trigo, necesitado de agua y tierras húmedas, tocaba en octubre y noviembre para recolectarse en mayo y junio. El almacenaje de ambos cereales soportaba en promedio un año y medio, siempre y cuando se atendiera la precaución a la exposición de plagas. Las remuneraciones al trabajo promediaban dos reales al día, habiendo variaciones circunstanciales. Las labores campiranas eran atendidas por peones, arrendatarios, medieros o por sus dueños. En sí, la economía de la región de Puruándiro era natural, frágil y subalterna de la naturaleza debido a la escasa capacidad tecnológica prevaleciente. $^{3}$

\section{FORMAS DE ARRENDAMIENTO}

EN EL CAMPO PURUANDIRENSE

La región de Puruándiro en el siglo XIX iba dejando de ser una economía natural y de consumo propio transitando hacia una de tipo mercantil, orientada al comercio y a la procuración de un rendimiento. Atendiendo a esta transformación, la renta de la tierra, a pesar de asumir el compromiso triple conocido de pago en trabajo, género y metálico, se ajustaba a una flexibilidad de acuerdo a las circunstancias. Igual carácter priva en propietarios, arrendatarios y operarios. Ni el primero se mantiene al margen de la producción debido a que atiende otras actividades relacionadas, ni el siguiente adquiere el control de la propiedad al no asumirse como empresario, y el último, no es sólo el trabajador agrícola dependiente de los ingresos de una relación laboral exclusiva pues existen otros medios de ingreso personal exteriores (p. 40-41).

Las 110 partidas notariales utilizadas definieron la intrincada variedad del arriendo rural. La dimensión del alquiler va más allá de la mera cesión en usufructo de la tierra pues ésta es un factor más contenido en toda la unidad productiva en la que también cuentan otros agentes que la hacen atractiva como explotación racional (p. 41).

La sistematización del material de archivo de acuerdo a cinco tipologías de propiedad consistentes en haciendas, fracciones de hacienda, ranchos de hacienda, ranchos independientes y terrenos, permitió revelar que en la región de Puruándiro el arrendamiento se contrataba en plazos habituales de entre 5 y 9 años de duración; la liquidación de la

5. Moreno García, op. cit., 1992a. p. 54. 
renta era en general anual y en efectivo; y los arrendatarios eran individuos $\mathrm{en} \mathrm{su}$ mayoría de la misma región. Los rubros de mejoras y de utilización de recursos dependieron del tipo de propiedad y de la condición del propietario, explicación a la gran variedad de las condiciones especificas presentes en los contratos (pp. 44$59,66)$.

Finalmente Moreno concluye que la práctica del arrendamiento en Puruándiro representó para los cinco tipos de propiedad "un recurso que pudiera calificarse casi como estructural; si no en la producción y manejo laboral y administrativo de la finca, sí en la complementación de la economía" (p. 67).

\section{ASOCIACIONES DE PARTICIPACIÓN}

RURAL EN PURUÁNDIRo

La creación formal de pequeñas asociaciones establecidas para funcionar en el ámbito rural de Puruándiro era algo frecuente. La forma usual de esas compañías rurales, de fachada y contenido rudimentario, se asemejarían a las denominadas sociedades de participación, sancionadas por la ley, como asociaciones de dos o más personas con objetivos y duración temporal muy precisos (p. 58)

La intención de las compañías respondía a labores específicamente rurales, agrícolas y pecuarias; y en menor medida comerciales, industriales y crediticias. Los convenios definidos por intereses específicos en cada ocasión determinan la intervención de los socios sobre la incorporación del capital constante y el variable, a la vez que la coordinación de los cargos asumidos por el socio capitalista e industrial (pp. 59-60).

Lo normal era que las ganancias generadas se repartieran por partes iguales entre los socios, pero se aceptaban también ciertas adecuaciones. Las pérdidas y otros gastos se ajustaban de igual manera. (pp. 61-62) Los pactos sobre el vencimiento de las sociedades oscilaron entre 1 y 9 años con inclinación a lapsos de 3 a 5; y la finalidad de ellos quedó bien manifiesta al estipular trabajos de molino, cultivo de propiedades y cuidado de ganado (p. 62).

Los socios, aunque en su mayoría designados como "labradores", representaban a diversos grupos sociales que actuaban en una intrincada red de relaciones de intercambio entre el campo y la ciudad. Sus sitios de procedencia distinguen y establecen relaciones de otras regiones con la de Puruándiro, tan es así que Moreno apunta el reflejo de lazos de intercambio entre el núcleo regional rural (Puruándiro), otras poblaciones aledañas y el medio urbano allende (p. 64). 
Al final de cuentas estos arreglos en el ámbito rural de Puruándiro son muy parecidos a los negocios formales en participación. Se trata de procesos administrativos más aptos, pues, según Moreno, “cuadraba mejor con un tipo de economía campesina en el que todavía tiene preponderancia la propiedad fundiaria sobre la propiedad de capital y en que la tierra todavía representa la mayor seguridad para la riqueza y la inversión de los dinero-tenientes" (p. 65).

\section{EL CRÉDITO PRIVADO COMO ELEMENTO} CONSTITUTIVO DE LA FORMACIÓN REGIONAL

Uno de los factores constitutivos de la región económica, aparte del geográfico, el económico y jurisdiccional, es el crédito rural.

La gama de los prestamistas y prestatarios en la región de Puruándiro, atendiendo a Moreno, es en cierta forma homogénea debido a la presencia de elementos rurales y citadinos asumidos más bien en su actividad campirana que en categorías sociales (pp. 30-31). Intención siempre prevaleciente entre cualquier contratante rural.

El crédito al sector agrario en Puruándiro más que provenir de instancias institucionales, apenas un $8 \%$ del total, procedía de fuentes particulares. Así te- nemos que un $35 \%$ derivó del grupo de comerciantes; 16.2, de profesionistas; y significativamente, un substancial 40.1 del mismo sector rural (p. 31). El destino de los préstamos es bastante claro pues un $94 \%$ del crédito global fue para actividades relacionadas con la tierra (pp. 31$32)$.

Es interesante diagnosticar los procedimientos lineales de concesión-pago-recuperación inherentes al crédito en la campiña puruandirense. En general el esquema era de dinero por dinero con interés garantizando el préstamo alguna posesión, consistente en una hacienda, rancho o terreno. Pero la diversidad de arreglos no únicamente se concretó de esta manera, un significativo número de contratos asumieron diversas modalidades. Tanto unas como otras presentan la dificultad de enmarcarlas dentro de relaciones precapitalistas o capitalistas en el agro, pues no hay claridad para aseverar esto o aquello. De una cosa si puede estarse seguro, las viejas prácticas campiranas confiadas en tratos personales, en donde la palabra y el honor son la mejor garantía, se comienzan a diluir a partir del último tercio del siglo para dar paso a la fe notarial (pp. 32-33).

Los vencimientos de los préstamos conllevó plazos en segmentos de 1 año y menos (corto), de 2 a 5 años (mediano) y 
de aquí hasta 10 (largo), arrojando índices porcentuales de 19.3, 58.8 y 21.7, respectivamente. Esta categorización demuestra que la recuperación del crédito se fijaba a lapsos intermedios. En tanto la tasa impositiva fluctuó en cifras del 5, 6 y $12 \%$ anual, como signos constantes, aunque hay que reconocer algunos casos con otros índices que respondieron a un carácter más eventual (p. 34).

El patrón de préstamos en Puruándiro durante el siglo XIX experimentó un cambio significativo entre 1908 a 1910, años críticos para el campo mexicano. Las magnitudes de los créditos que previamente habían privilegiado a las haciendas se modifican en favor de ranchos y terrenos. La reversión de la tendencia puede entenderse por la búsqueda de una mayor seguridad, evitando las contingencias del momento, condiciones que las unidades medianas y pequeñas parecían ofrecer de manera suficiente (pp. 35-36).

\section{TENENCIA Y MOVILIDAD DE LA TIERRA EN}

\section{EL BaJío MichOACANO EN EL SIGLO XIX}

No hay duda, los cambios en la tenencia de la tierra influyen de diversas formas en la estructura agrícola y Moreno esta consciente de ello al disponer como herramienta de análisis de 319 escrituras notariales.
Tres son las categorías en que se dividen los bienes fundiarios, entre $1830 \mathrm{y}$ 1910, en el artículo: las grandes propiedades (haciendas y fracciones de estas); los ranchos (dependientes o independientes) y los terrenos.

La transferencia de las haciendas, íntegras o fraccionadas, siguió una clara trayectoria ascendente en el período de estudio, en parte debido a una reproducción importante de los capitales, a pesar de que los volúmenes manejados no son considerables en comparación con otras regiones del país, no obstante son significativos. La cercanía a los centros de consumo urbanos más importantes concedía ventajas para la fácil trasferencia de algunas propiedades, mientras que las haciendas alejadas de esos centros se vendían con más dificultades (p. 267).

Una constante encontrada por Moreno que confirma la antigua afirmación sobre la reticente movilidad de las haciendas mexicanas se corrobora. Sin embargo la propuesta de él enfila hacia otras causas. La idea colonial de los propietarios, persistente en el siglo XIX, sobre la dominación del poder social y político por el control ejercido sobre la tierra, impidió en cierta medida la movilización de ésta. Contrariamente una serie de factores, como problemas financieros y endeudamiento ocasionados por múltiples cir- 
cunstancias, apostaban en el otro sentido, la desarticulación podría presentarse desde la venta de fracciones hasta la enajenación total (p. 259). También los procesos hereditarios intervenían en la dirección de la desmembración de una finca (pp. 261-262).

Las haciendas del Bajío michoacano guanajuatense en general fueron de extensiones modestas, en casos especiales de propiedades que excedían la superficie promedio, la venta completa se enfrentaba con la incapacidad de encontrar adquirientes debido a la relativa falta de capitales suficientes, convirtiéndose en un factor más que imponía el fraccionamiento incondicional (pp. 262-263).

En contrapartida, el rancho figuró como un tipo de propiedad bastante común en la región de Puruándiro en el siglo XIX, muy por encima en número de unidades sobre las haciendas. Al igual que las grandes propiedades la movilidad de los ranchos atendía a cuestiones de cercanía a los centros urbanos como Puruándiro. Similar trayectoria en el mercado de bienes raíces experimentaron las medianas propiedades respecto a las de una mayor extensión, al observarse un proceso ascendente de comercialización conforme transcurría el siglo (pp. 267-268).

El listado de los contratos de compraventa, levantado por Moreno, indica que los terrenos son en todo el período los que registran las cifras de intercambio más intenso, no así los capitales destinados a estas operaciones, en donde las haciendas y los ranchos registran sumas generales muy superiores. En todo caso la liquidación de los haberes se presentan en sentido contrario, pues mientras en las grandes propiedades generalmente procedió la transacción mediante hipoteca, en los ranchos se cubrió en efectivo un $80 \%$ y en los terrenos el pago se realizó en un $95 \%$ al momento del convenio (pp. 271-272).

Las inversiones tuvieron un origen bastante interesante en el mercado de tierras en Puruándiro. Los flujos monetarios provinieron en términos absolutos en un $86 \%$ de la zona misma, mientras el resto, un $14 \%$, resulto de un abanico de lugares vecinos y apartados. La revelación estriba en la generación interna de capitales y su inversión en la adquisición de propiedades rústicas. No obstante, este resultado debe matizarse pues las aportaciones foráneas globales crecen conforme termina el siglo y llegan a alcanzar un 23\% (pp. 272-273). Por otro lado, la procedencia sectorial demuestra que el $57 \%$ de las adquisiciones la realizaron individuos dedicados a labores del agro; asombra, en contra de los esperado, que apenas un $18 \%$ corresponda al capi- 
tal comercial; y el resto, un $25 \%$, provino de personas con ocupaciones diversas (p. 274).

\section{LA TECNOLOGÍA AGRÍCOLA EN LA REGIÓN DE PURUÁNDIRO}

Este artículo viene a incorporarse a los estudios de los problemas agrícolas en México durante el siglo XIX. Los temas sobre las técnicas utilizadas en la agricultura siguen desprovistos de una historiografía suficiente. Una de las razones de ello es la escacez y la pobreza de la documentación directamente referida a ese tema.

$\mathrm{El}$ inconveniente Moreno lo resuelve aprovechando otras fuentes alternas correspondientes a inventarios de las propiedades rurales que se conservan en los archivos de Michoacán. De esta manera, con una masa de 46 inventarios, el autor procedió a realizar su análisis.

En principio todo indica que la única fuerza de tracción utilizada en las labores rurales de las haciendas de Puruándiro eran las bestias de tiro. El número de animales existentes en cada unidad productiva dependió de variables como sus dimensiones, la extensión de las tierras abiertas al cultivo, la eficiencia administrativa, la escala de comercialización alcanzada, la cercanía a los grandes cen- tros de consumo y administrativos y el desarrollo de los mercados regionales (pp. 89-94).

Los propietarios mas modestos no utilizaban bueyes sino otros animales de arada, en detrimento de una adecuada roturación del campo y por ende de los resultados, sin considerar además otras ventajas relacionadas a las labores del campo. Esta circunstancia impuso una relación de dependencia de aquellos con poseedores que ofrecían las yuntas en alquiler. No obstante, lo aclara bien Moreno, puede estimarse en $60 \%$ los parvifundistas que poseían la tracción animal necesaria y en ciertos casos excedían sus necesidades regulares (pp. 94-97).

A través del siglo XIX en la región de Puruándiro no se presenció un giro técnico en los utensilios de trabajo de las haciendas. Moreno encontró la mismos enseres tradicionales utilizados en los cultivos en épocas pasadas. Ni pensar en implementos importados, al menos hasta los años ochenta. Yugos y arados de madera (probablemente de fierro a partir de 1880), arados, barzones, palas, azadones y hoces, eran las existencias instrumentales habituales enlistadas en los inventarios. Otra relación de herramientas aparte son enlistadas siempre como auxilio de otras actividades conexas de las fincas. La continua inestabilidad social del siglo 
impidió un aumento y mejoramiento de los arsenales de trabajo (pp. 97-99), aunque esto se refiera a la región en su conjunto, sin considerar el caso de propiedades más o menos "tecnificadas".

Las razones para este débil desarrollo tecnológico son varias: la abundancia de mano de obra barata; la fertilidad de los suelos que permitía una agricultura extensiva; la baja demanda de los mercados que evitaba los incentivos en el incremento de la producción; y la innecesaria utilización de innovaciones en cultivos que descansaban en la explotación sancionada por la costumbre (p. 101, 103).

$\mathrm{Al}$ igual que los hacendados, los rancheros y demás agricultores se abstuvieron de incorporar novedosos equipos técnicos. Es más, los enseres de trabajo utilizados por ellos eran más modestos en número y calidad que los de ciertas haciendas. Tal vez el balance global de los inventarios de estos dominios nos dimensione la magnitud del rezago, al encontrarse que el $70 \%$ no disponía ni siquiera de los utensilios indispensables para laborar (pp. 105-106).

\section{COMENTARIOS FINALES}

Los cinco artículos reseñados de Heriberto Moreno García sin duda merecen igual atención por parte de los investigadores, que la prestada a sus otros trabajos más conocidos de tema agrario y agrícola.

Los aspectos revisados exhiben parte de la complejidad rural de una región del Bajío durante el siglo XIX y es evidente que los resultados en su momento eran provisionales, de allí la presencia de algunas imprecisiones, debidas más al carácter de primicias que a una falta de rigor del autor.

El espíritu y las hipótesis que animaban el trabajo de Heriberto Moreno merecen ser retomadas en otros ámbitos geográficos y temporales, convirtiéndose en una invitación a continuar la historia del agro mexicano bajo otros enfoques. Su propuesta de explorar la historia como problema sigue vigente.

Alfredo Lopez Ferreira EL COLEGIO DE MICHOACÁN-UNIVERSIDAD AUTÓNOMA DE AGUASCALIENTES 
